Article

\title{
Development of a Framework for Activation of Aggregator Led Flexibility
}

\author{
Sarah $\mathrm{O}^{\prime}$ Connell ${ }^{1, *(1)}$ and Marcus Martin Keane ${ }^{2}$ \\ 1 Faculty of Engineering, Institute of Technology Carlow, R93 V960 Carlow, Ireland \\ 2 Informatics Research Unit for Sustainable Engineering, Ryan Institute at National University of \\ Ireland Galway, National University of Ireland Galway, H91 TK33 Galway, Ireland; \\ marcus.keane@nuigalway.ie \\ * Correspondence: oconnells@itcarlow.ie
}

check for updates

Citation: O'Connell, S.; Keane, M.M. Development of a Framework for Activation of Aggregator Led Flexibility. Energies 2021, 14, 4950. https://doi.org/10.3390/en14164950

Academic Editor: Spyros Voutetakis

Received: 7 July 2021

Accepted: 9 August 2021

Published: 12 August 2021

Publisher's Note: MDPI stays neutral with regard to jurisdictional claims in published maps and institutional affiliations.

Copyright: (C) 2021 by the authors. Licensee MDPI, Basel, Switzerland. This article is an open access article distributed under the terms and conditions of the Creative Commons Attribution (CC BY) license (https:// creativecommons.org/licenses/by/ $4.0 /)$.

\begin{abstract}
This paper presents a novel framework architecture for an online, real-time flexibility assessment and activation platform targeted at unlocking the flexibility potential of commercial buildings and smaller industrial sites, thereby enabling greater levels of renewable grid integration. Renewable integration targets in Europe of up to $40 \%$ of power generation from renewable sources by 2030 and over $90 \%$ by 2050 aim to decarbonize the electrical grid and increase electrification of transport, industry, and buildings. As renewable integration targets increase, participation in flexibility programs will be required from a much greater range of buildings and sites to balance grids hosting high levels of renewable generation. In this paper, an online implementation of a standardized flexibility assessment methodology, previously developed for offline contract negotiations between stakeholders, is modified to automate the assessment. The automated assessment is then linked to an aggregator-based multi-building or site optimization stage, enabling increased participation of multiple buildings and sites. To implement the assessment, models for individual flexible systems were reviewed, selected, and adapted, including physics-based, data-driven, and grey-box models. A review of optimization for flexibility found mixed-integer linear programming to be the optimal approach for the selection of flexible systems for demand response events.
\end{abstract}

Keywords: energy flexibility; demand response; aggregator; data-driven models; mixed-integer linear programming

\section{Introduction}

The electrical grid is changing, primarily in response to the need for balancing increasing amounts of renewable generation. Renewable integration targets in Europe of 38 to $40 \%$ [1] of power generation from renewables by 2030 and $90 \%$ by 2050 [2] are being used as the means to decarbonize the grid and increase electrification of transport, industry, and buildings. Energy and power flexibility provided by industrial sites and a range of building types [3] is more cost-effective for grid management than strategies such as curtailment or gas-fired generation [4]. Current practice in power systems demands response programs is to utilize flexibility from a few large industrial sites [5]. Enabling renewable generation hosting capacities of over 65\% [6] requires participation from a much wider spectrum of buildings such as offices, retail, apartment blocks, and single residential buildings [7] as well as industrial sites. These buildings and sites will be required to provide greater numbers of flexible systems and deeper ranges of flexibility [8].

Aggregators provide energy and power balancing services by acting as an intermediary between a contracting authority, typically a grid utility, and buildings or sites connected to the electricity grid [9]. The aggregator puts together a portfolio of sites to meet the minimum power or energy participation criteria set by the contracting authority to provide flexible services such as demand response (DR) to the grid [10]. Power and energy flexibility of grid-connected loads, generation, and storage has become increasingly 
important for grid utilities hosting larger capacities of renewable power generation on the grid [11]. The role of the aggregator is to offer an increased or decreased load, quantified in terms of electrical power (in $\mathrm{kW}$ or $\mathrm{MW}$ ) and duration (time) to the grid utility in return for a financial payment [12], thereby enabling the grid utility to balance the grid, increase renewable hosting capacity and provide grid stability for the users of the electrical network [13]. Larger portfolios of buildings and sites with higher diversity factors and lower correlation between sites are more beneficial [9] as they enable aggregators to improve forecast performance, mitigate uncertainties, and reduce risk costs [14], thus resulting in more cost-effective bids for demand response programs. At present, aggregators contact each building or site individually, and coordination is resource-intensive [5]. If an automated framework were available, with all sites in an aggregators' portfolio continuously connected, it would be a key enabler for the provision of flexibility services, unlocking the underutilized potential [15] of smaller buildings and sites.

This paper proposes the automation of a flexibility assessment methodology previously developed by the author [16] combined with elements of an approach developed for the management of flexible grid resources [17]. The flexibility assessment methodology [16] consists of a four-step process that quantifies the available flexibility at a building or site offline, enabling contract negotiations for demand-side services between building operators and aggregators. This paper adapts the methodology for the development of online real-time flexibility assessments by automating the data collection, flexibility characterization, and scenario modeling steps from the assessment and coupling these with an aggregator-based multi-building or site optimization stage. In the framework, buildings and sites are continuously connected, and the implementation of flexibility has been fully automated from grid-level through to building or site systems. The methodology may be implemented automatically online and in real time if (i) specific steps in the methodology were automated and (ii) acceptability barriers and interoperability technology gaps [18] were overcome. This paper aims to address (i). An aggregator-based implementation is proposed, but a building-based implementation is also feasible. The approach for automating steps of the flexibility assessment methodology is to develop models for individual flexible systems and input these into an optimization algorithm. The flexible systems selected were a heat pump, air handling unit (AHU) fans, photovoltaic (PV) on-site renewable generation, and a lithium-ion battery storage system.

The remainder of this paper is organized as follows: Section 2 outlines the development of the Aggregator Based Framework. Section 3 reviews modeling approaches for different flexible systems, selects the most appropriate model types, and adapts them for flexibility. Section 4 addresses the optimization requirements and reviews approaches for flexibility, while Section 5 details the conclusions.

\section{Aggregator Based Framework}

\subsection{Framework Structure}

An aggregator-based framework for automated implementation of the flexibility assessment methodology is shown in Figure 1. The system is to operate in an online realtime manner and be hosted in the cloud. When a demand response request is received by the aggregator (denoted AGG in Figure 1) from a grid operator, the software automatically verifies flexibility contracts with the buildings in its portfolio to determine which are valid for the particular demand response program the request relates to. Smart contracts developed for grid energy trading [19] or peer-to-peer energy trading [20] modified for flexibility may be implemented for the contract verification stage. The cloud-based platform then contacts the on-site automation system in the relevant buildings or sites to read data from the systems in the buildings. On-site automation systems in buildings are typically a form of building management system (BMS), whereas, in industrial sites, a supervisory control and data acquisition (SCADA) system may be installed. The aggregator-based framework then implements "Step 1: Identification of flexible sources, loads, storage and generation" from the standardized flexibility assessment methodology [16]. Step 1 
is applied to the data for each of the buildings or sites individually. "Step 2: Flexibility Characterization" is conducted in an automated manner to quantify the available flexibility at each building or site. "Step 3: Scenario Modelling" then models the systems and outputs the available flexibility defined for the specific time period of the demand response request for each building or site. The available flexibility is then input into the aggregator multibuilding optimization algorithm, which selects the most appropriate buildings, sites, and sources for the event. The aggregator platform decides to accept or reject the flexibility available and a write signal to actuate sources is sent to the BMS systems in each selected building or site.

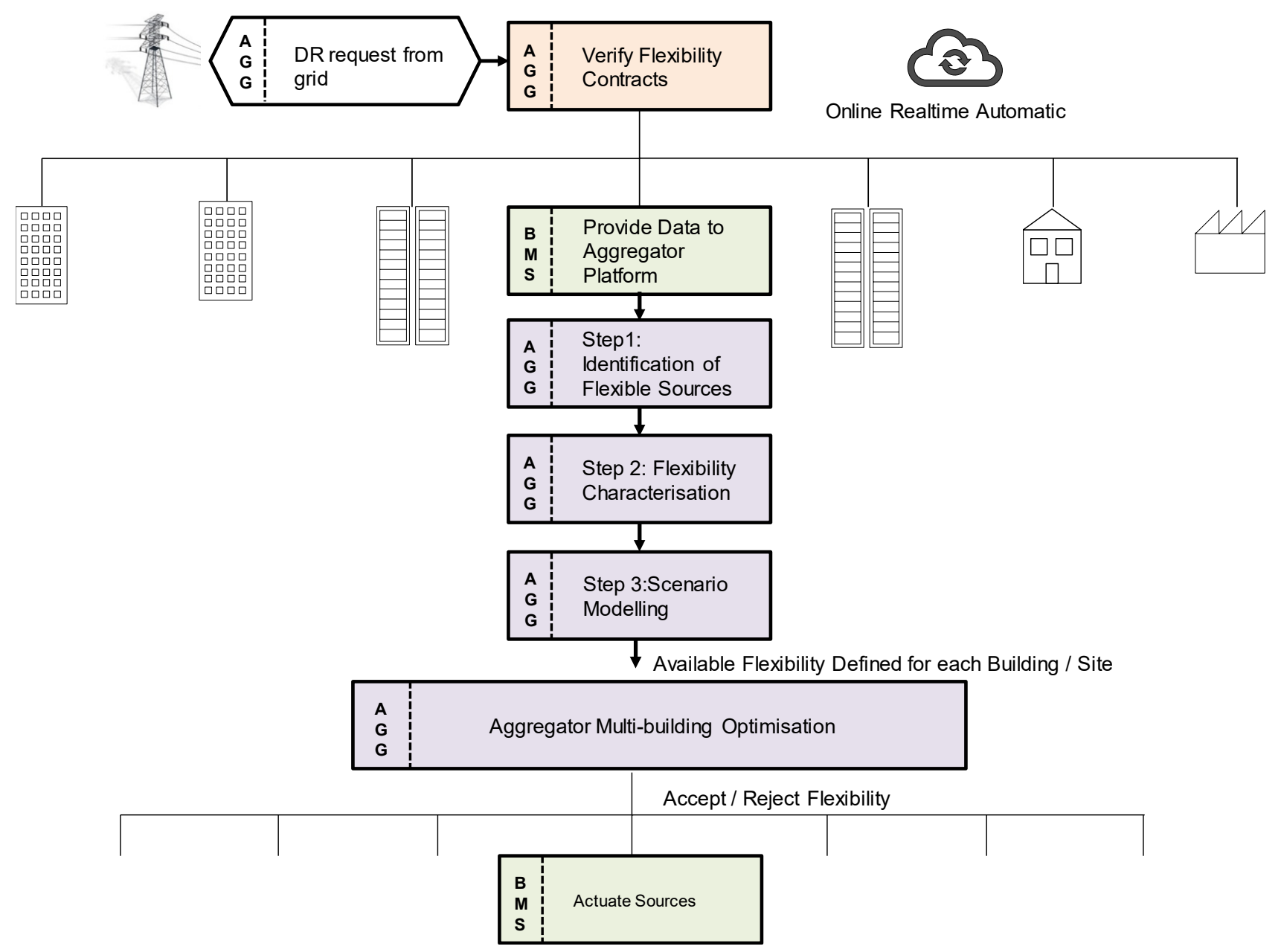

Figure 1. Aggregator-based online real-time automated implementation of flexibility assessment.

Making buildings truly smart for flexibly may be more cost-effective if cloud-based solutions are utilized. Connecting multiples of buildings to a single cloud-based platform that implements the flexibility assessment methodology proposed in this work may accelerate the rollout of flexibility for commercial and residential buildings as it will reduce cost by (a) achieving economies of scale and (b) minimizing modifications to existing BMS systems. Economies of scale [5] would enable a single platform to compute flexibility simultaneously for many buildings or sites. Minimizing expensive and time-consuming modifications to existing BMS systems in the buildings would reduce costs [18]. These would enable online real-time flexibility quantification for both buildings and aggregators. Alternatively, a combination of cloud and edge-based [21] implementation may be deployed to increase the computational efficiency and response time of flexible systems. 


\subsection{Use Cases}

Practical examples of use cases that may be implemented using the framework are detailed below.

\subsubsection{Dynamic Pricing}

Under the EU's 2019 Electricity Directive, all member states will be required to provide dynamic pricing for customers with a smart meter [22]. Dynamic or real-time pricing, whereby the electricity tariff may change frequently based on grid balancing requirements due to renewable generation or load fluctuations, will create scope for active optimization and management of large numbers of small flexible resources [23]. This may be implemented with or without contracts with grid operators or regulators. Flexibility programs based around dynamic or real-time pricing already exist for large commercial customers in a number of countries. For example, in Ireland, a market-based program that requires the building or site to respond to a grid request intra-day within a short timeframe is the short-term active response (STAR) program [10].

\subsubsection{Peak Shaving}

Peak shaving is a price-based program whereby the contracted building or site agrees to reduce its load at the same time every day during peak demand. It is the most widely used demand response service globally, with Ireland [10], the US [24], and China [25] including it in their demand-side services. In Europe, the demand peak occurs during the winter [10] due to heating loads, where in the US, the peak occurs during the summer due to cooling loads [24]. With peak shaving, the building operator knows the price and time schedule, sometimes more than a year in advance.

\subsection{3. $\mathrm{CO}_{2}$ Minimization}

$\mathrm{CO}_{2}$ based demand response signals have been proposed as a mechanism to increase electricity use or reduce consumption, in times of high or low renewable generation on the grid [26]. An alternative to, or in combination with, price-based signals, they may be utilized in future markets where hourly or real-time generation emissions are available. Motivations for adoption include enhancement of carbon reduction strategies by businesses or citizens who wish to minimize their climate impacts, or for grid operators to maximize renewable generation consumption.

\subsubsection{PV Power Smoothing}

PV power smoothing is used to dampen fluctuations in power generation caused PV variability by using battery storage to compensate for the peaks and troughs [27]. It requires storage coupled with PV and may be activated at the request of the grid operator or may be implemented continuously. The objective of this use case is to smooth PV peak production by storing excess renewable electricity generated or discharging storage to compensate for sudden reductions in output. With the aggregator-based platform, the PV installation and the storage may be in different buildings or sites but coordinated centrally, subject to agreements with grid operators.

\section{Modelling Approaches}

Automating the generation of models for Step 3: Scenario Modeling, which calculates the maximum and minimum flexibility required for the specific event, is required to implement the methodology in an online real-time way. The approach proposed herein is to implement models for specific systems in conjunction with an optimization formulation. A range of potential modeling approaches were identified for a number of flexible systems. Models were evaluated to enable the selection of the most suitable modeling approach for each system. The model types and flexible systems included (1) data-driven predictive model applied to air handling unit (AHU) fan control; (2) a grey box model applied to thermal building systems, specifically heat pumps; and (3) a physics-based model 
with parameter estimation applied to Photovoltaic (PV) renewable generation; and (4) an electrical model applied to the battery system.

In an online real-time scenario, when a signal is received from an aggregator requesting to be informed of the available flexibility, the models are activated or are continuously predicting, and the outputs are input to the optimization algorithm. The model outputs consist of the available power flexibility for the time period of the demand response request for each system. The optimal combination of systems is then selected by the optimization algorithm.

The models have been chosen to minimize data gathering requirements both in (a) number of variables and in (b) length of time series required for prediction. For example, the internal power electronics of the battery system are not required to be modeled as this would have very little impact on the available flexibility provided by the battery and would make for a computationally expensive model. Losses internally in the system may be modeled through the use of the charging efficiency and modeling of the discharging efficiency.

Interactions between systems may be accounted for either in the models or at the optimization stage. For the combination of systems under consideration in this work, there may be an interaction between the thermal systems such as heat pumps and ventilation fans. Changing the AHU fan speed may cause interactions with the variable refrigerant flow (VRF) heat pump system. This may be accommodated by using the predicted fan speed as an input to the grey box model for the thermal building system. There would then be two model outputs for the thermal system, one with standard fan speed and one with modified fan speed.

Occupant comfort requirements may be incorporated in the grey box thermal model. Indoor air temperatures are required to stay within adaptive comfort boundaries as defined in ASHRAE 55 [28] or other adaptive comfort standards such as EN 15251 [29], or maximum $\mathrm{CO}_{2}$ levels may be specified in accordance with CIBSE guidelines [30].

\subsection{AHU Fan Model}

A data-driven model may be suited to modeling the electrical power of an AHU fan to predict its flexibility. The relationship between electrical power and ventilation rates is less complex than thermal systems, and provided any change in fan speed is linked to the thermal system model to ensure interactions are captured the model may rely on data. Seasonal effects are not as impactful, as ventilation requirements may be independent of outside air temperature, and a number of approaches are possible depending on the control variable for the fans.

Of the data-driven modeling approaches available, autoregressive-exogenous (ARX) [31] and autoregressive moving average (ARMAX) [32] models are the most commonly used for simulation of building energy consumption. Reviews of data-driven modeling approaches in buildings include numerical models for the prediction of electrical loads in buildings [33], regression models [34], energy prediction in buildings [35] as well as large-scale datadriven modeling of energy in buildings [36]. Zeng et al. [33] found that multivariate linear regression and non-linear support vector machines produced better results, particularly when buildings had unpredictable and multifaceted patterns of energy consumption.

Focusing specifically on the requirements for a data-driven model of an AHU fan, previous studies used $\mathrm{CO}_{2}$ data to predict occupancy [37] or occupancy and ventilation rate to predict $\mathrm{CO}_{2}$ concentration [38]. However, a model for flexibility would need to be different as the objective is to predict fan power from $\mathrm{CO}_{2}$ data.

For the development of the model, if the fan is controlled at a fixed speed setpoint only, the setpoint may be reduced subject to constraints, and the model may be simple. If the fan speed is controlled by $\mathrm{CO}_{2}$, a data model using $\mathrm{CO}_{2}$ measurements as an input may be appropriate, subject to the constraint of a $\mathrm{CO}_{2}$ limit, e.g., $1000 \mathrm{ppm}$ [30]. The data-driven model may also be correlated against occupancy so that the predicted fan speed "learns" occupancy if occupancy data is available. The fan speed setpoint $\mathrm{s}$, then determines the 
power consumption of the fan during the event. To determine the available fan flexibility, $f_{F}$ in $(\mathrm{kW})$, the following formula may be used:

$$
\begin{gathered}
f_{F}=P_{c}-P_{p} \\
P_{p}=f\left(\mathrm{CO}_{2}\right) \cdot \mathrm{s}
\end{gathered}
$$

where $P_{C}$ is power at current fan speed and $P_{p}$ is predicted fan power, a function of $\mathrm{CO}_{2}$ concentration. The recommended control variable is the fan speed. The model objective is to maximize the power reduction by the fans, subject to $\mathrm{CO}_{2}$ constraints. Training data may be taken from representative days rather than all days [39], for example, weekdays with typical occupancy.

\subsection{Thermal Systems Model}

Modeling the electrical response of thermal systems in the building is a complex process that typically requires detailed thermal modeling of the building physics, known as white-box models [40]. As was seen in the previous section, data-driven models, sometimes referred to as numerical or black-box models, have also been used [31-36] but (i) parameter identification may not map to real parameters in the building, e.g., thermal conductivity, and (ii) prediction is reliant on the quality and diversity of the data available. In recent years, a number of grey box modeling approaches have been developed which combine knowledge of building physics with some data-driven aspects. The most common type is an R-C model, an analogy of the resistance-capacitance approach of electrical circuits. Grey box model libraries for building energy have been developed in the modelica modeling language by a number of research institutions [41-44]. An alternative R-C approach is the state-space model developed by Bacher and Madsen [45]. Other grey box approaches start with complex whole building simulations such as EnergyPlus, and reduce model complexity incrementally until the model is computationally efficient [46] and meets operating requirements. Computation times required for prediction horizons for some of these approaches are long, $80 \mathrm{~h}$ for full model reduced to $3 \mathrm{~h}$ for simplified model [25], which may be too long for intra-day flexibility events of $1 \mathrm{~h}$ or less.

The recommended control variable for thermal systems modeling is the global indoor air temperature set point. The model objective is to determine the electrical power reduction or increase that can be achieved for a specific change in temperature set point. Input parameters include outside air temperature and may include weather-related data, e.g., solar radiation, wind, relative humidity, and occupancy data.

The state-space model developed by Bacher and Madsen [45] and implemented by Roels et al. [31] uses a grey box approach based on the R-C principle. It starts with fitting a simple model and adding additional terms to simulate additional physical parameters, e.g., solar radiation or wind, until the loglikelihood plateaus and residuals are equivalent to white noise. The loglikelihood or maximum likelihood estimation is a statistical function which represents the combination of parameters which maximize the goodness of fit of a statistical model. Two potential implementations of this model are proposed. The first adapts the model for electrical power. The second implementation is specifically for a heat pump application and uses the temperature output of the state space model as an input to the heat transfer equation, applying the heat output to Coefficient of Performance (COP) to calculate power reduction or increase. To implement the state space approach for power flexibility, the model would need to be adapted to focus on electrical power, $P$, instead of temperature, $T$ as shown in Equation (3):

$$
d P=A P d t+B U d t+C T d t+d \omega
$$

whereby the state vector is $P$, the input vector is $U, T$ the Temperature vector, and parameter vectors are denoted $A, B$, and $C$. $\Phi$ is the energy flux from solar radiation $s$, and heating 
system $h$. The Weiner process, assumed to be a Gaussian white noise process analogous to an error term, is denoted by $\omega$.

$$
U=\left[P_{a} \cdot \Phi_{s} \cdot \Phi_{h}\right]^{P}
$$

The second approach is to use the un-adapted state-space model for determining temperature changes only, then input these into the heat transfer equation to calculate the heat reduction or increase:

$$
Q=\dot{m} C_{p} d T
$$

where the mass flow rate is $\dot{m}$ of the heat transfer fluid, typically refrigerant, water, or a water-glycol mix, and $C_{p}$ is the specific heat capacity at a constant pressure of the heat transfer fluid. COP is then used to calculate electrical power, $P$ :

$$
C O P=Q / P
$$

Thermal system flexibility, $f_{T}$, equivalent to $\mathrm{x}$, the proportion of flexible power, by $P$, the electrical power consumption of the heat pump, is calculated as:

$$
f_{T}=x * P=Q / C O P
$$

As $C O P$ varies with condenser and evaporator temperatures, heat pump or compressor power curves in lookup table format are required to define the relationship between $C O P$ and input-output temperatures.

\subsection{Photovoltaic (PV) Model}

A physics-based PV model such as that developed by Zhou et al. [47] may be used to predict the output of the PV installation. The key inputs are solar irradiance and peak installed capacity. The model incorporates the PV curve with a thermal drop-off effect and a number of characteristic parameters of PV modules. Parameter estimation was included. Forecasts for solar irradiance may be obtained from subscription services [48]. Another option for modeling PV output may be to deploy learning algorithms based on weather forecasts [49]. For both model types, the key to accurate prediction is reliable solar irradiance forecasts. Accuracy of prediction of PV output is dependent on the accuracy of the solar irradiance forecasting at the exact position of the PV installation. Ito et al. [50] adopted a geographical area approach for predicting the output from large-scale gridconnected PV, for example, one prediction point per region. A building scale PV model which incorporates partial shading [51] may account for extremely localized effects such as a cloud passing over the building and may be more beneficial in this context.

A control variable is not required for PV as the output of the panels is not controllable. The objective of the model is to predict the power output of the PV installation for a given predicted solar irradiance. The model proposed by Zhou et al. [47] determines the power output for an array, $P_{A}$, based on the number of parallel-connected modules $N_{p}$ and the number of series-connected modules $N_{s}$.

$$
f_{P V}=P_{A}=N_{S} \cdot N_{p} \cdot P_{M}
$$

The PV module maximum calculated power output, $P_{M}$, given solar irradiance $G$, is defined as

$$
P_{M}=\frac{v_{o c}-\ln \left(v_{o c}+0.72\right)}{1+v_{o c}} \cdot\left(1-\frac{R_{s}}{V_{o c} / I_{s c}}\right) \cdot \frac{V_{o c 0}}{1+\beta \ln \frac{G_{0}}{G}} \cdot\left(\frac{T_{0}}{T}\right)^{\gamma} \cdot I_{s c 0}\left(\frac{G}{G_{0}}\right)^{\alpha}
$$

The series resistance is $R_{S}(\Omega), V_{o c}(\mathrm{~V})$ is the open-circuit voltage under normal solar irradiance $G\left(\mathrm{~W} / \mathrm{m}^{2}\right)$, while $V_{o c 0}$ is the voltage under the standard solar irradiance $G_{0}$. The normalized quantity of the open-circuit voltage with reference to the thermal voltage is $v_{o c}$. The short circuit current is $I_{S c}(A)$ while $I_{s c 0}$ is the short circuit current for $G_{0}$, the standard solar irradiance. The module temperature is $T(\mathrm{~K})$ and $T_{0}$ is the temperature of the PV 
module under standard solar irradiance $G_{0}$. Parameters $\beta, \gamma$, and $\alpha$ are constants for each panel type.

The angle of installation at which the PV panel is installed must also be considered and the difference between solar irradiance measured on the horizontal by a pyranometer located near the PV array calculated. The angle of declination will change during the day as the sun rises and falls, and over the year as the sun declines or rises in the sky. This may either be calculated or taken from a look-up table for a particular geographical location [52]. Parameter estimation for $\beta, \gamma, \alpha, n$ and $R_{S}$ at the maximum power point $(M P P)$ was conducted using experimental data, and the values determined [47]. $\alpha=1.21$, $\beta=0.058, \gamma=1.15, n M P P=1.17$ and $R_{S}=0.012 \Omega$. Other parameters may be identified from the PV manufacturer's datasheet [53], examples of which include the following: $P_{\max }=250 \mathrm{~W}_{\mathrm{p}}$ when $G=G_{0}, V_{o c 0}=37.8 \mathrm{~V}, I_{s c 0}=8.28 \mathrm{~A}, G_{0}=1000 \mathrm{~W} / \mathrm{m}^{2}, T_{0}=25^{\circ} \mathrm{C}$.

\subsection{Battery Model}

An electrical model was developed by the author for the battery system, starting from the mathematical model for a lithium-ion battery system developed by Berrueta et al. [54]. The detailed model was reduced to the essential elements as, for flexibility, the main priorities are high level, such as accounting for the round-trip efficiency losses in charging and discharging the battery system. Modeling internal aspects such as the kinetics of the chemical reaction or ion transport may be accounted for in the overall system efficiency. Power limits such as a minimum state of charge (SOC), required to be retained in the battery system for safety reasons, may be included as constraints in the model. Variations in power limits and overall efficiencies do occur and were determined to be significant by Sakti et al. [55] as constant efficiencies overestimated flexibility by $10 \%$ for electrical grid applications. A piecewise linearized model based on the R-C principle, developed by Gonzalez-Castellanos et al. [56], provides a means of determining varying real-time efficiencies and power limits for Li-Ion batteries. This may be coupled with the approach outlined below to calculate real-time efficiencies for both charging and discharging. Battery capacity also degrades over time, in particular, second-life electric vehicle batteries [57], and it is recommended that capacity be re-assessed during medium to long-term operation.

The model objective is to determine the maximum power increase or reduction the battery system can provide for a specified time period, assuming a constant rate of discharge over the time period. The recommended control variable is the charging or discharging rate in $\mathrm{kW}$ or $\mathrm{kVA}$. Two types of efficiency are to be considered, $\eta_{c}$ the coulombic efficiency during discharging and $\eta_{e}$ the energy efficiency during charging. The voltage charging the battery system is greater than the voltage discharging the battery system due to non-ideal processes, therefore, the efficiency losses are different. The flexibility of the battery system, $f_{B}$ may be modeled as shown in Equations (10)-(16).

General form:

$$
f_{B}=\frac{C \cdot S O C \cdot \eta}{\Delta t_{j}}
$$

Charging:

$$
f_{B}=\frac{C \cdot S O C \cdot \eta_{e}}{\Delta t_{j}}
$$

Discharging:

$$
f_{B}=\frac{C \cdot S O C \cdot \eta_{c}}{\Delta t_{j}}
$$

The energy capacity of the Li-ion battery is $C(\mathrm{kWh}), S O C$ is the State of Charge (\%), and $\Delta t_{j}(\mathrm{~h})$ is the duration of demand response event, $j$. To take into account active states of the battery, i.e., if the battery is already in the process of charging or discharging and will continue to do so between the time of flexibility measurement, $t_{0}$, and the commencement time of the demand response event, $t_{i}$ the terms identified in Equations (13) to (16) may 
be added to the model. $P_{c h}$ is the charging power $(\mathrm{kW})$ of the battery system, $P_{d}$ is the discharging power $(\mathrm{kW})$.

Flexibility event requests a discharge while the battery is charging (negative flexibility):

$$
f_{B}=\frac{\left(C \cdot S O C \cdot \eta_{c}\right)}{\Delta t_{j}}+\left(P_{c h} \cdot\left(t_{0}-t_{i}\right)\right) \cdot \eta_{e}
$$

Flexibility event requests a charge while the battery is charging (positive flexibility):

$$
f_{B}=\frac{\left(C \cdot S O C \cdot \eta_{e}\right)}{\Delta t_{j}}-\left(P_{c h} \cdot\left(t_{0}-t_{i}\right)\right) \cdot \eta_{e}
$$
bility):

Flexibility event requests a discharge while the battery is discharging (negative flexi-

$$
f_{B}=\frac{\left(C \cdot S O C \cdot \eta_{c}\right)}{\Delta t_{j}}-\left(P_{d} \cdot\left(t_{0}-t_{i}\right)\right) \cdot \eta_{c}
$$

Flexibility event requests a charge while the battery is discharging (positive flexibility):

$$
f_{B}=\frac{\left(C \cdot S O C \cdot \eta_{e}\right)}{\Delta t_{j}}+\left(P_{d} \cdot\left(t_{0}-t_{i}\right)\right) \cdot \eta_{c}
$$

where operational limits for the battery system, such as maximum and minimum charging $\left(P_{c}\right)$ and discharging $\left(P_{d}\right)$ power $P_{d, \text { minimum }}$ are less than $P_{d}$, which is less than $P_{d, \text { maximum }}$ and $P_{c, \text { minimum, }}$ which is less than $P_{c}$, which is less than $P_{c, \text { maximum }}$; minimum SOC and capacity degradation over time, may be modelled as constraints.

\section{Optimization}

Optimization using mixed-integer linear programming (MILP) has been utilized by a number of demand response applications. Scenario-specific objective functions [58], a stochastic approach [59], and applying models as constraints for the objective function for storage [31] are among the MILP formulations previously developed.

A data-driven flexibility function for characterization and control of energy flexibility was developed under the International Energy Agency (IEA) Energy in Buildings \& Communities Annex 67 on Energy Flexible Buildings [60]. This approach incorporates data-driven models of flexible systems in buildings and is dynamic in that the prediction of flexibility varies based on the data from the systems. As it is a data-driven approach, it may not be compatible with some of the grey box or physics-based model types proposed in this paper.

A formula for flexibility developed by the author [16] shown in Equation (17) may also be utilized as an objective function to maximize power flexibility for a given time period. The primary requirement for the objective function is that it be independent of use cases. Use cases may be addressed by varying constraints tailored to that specific use case.

$$
\max \sum_{s=1}^{n} f_{s}\left(t_{j}\right)
$$

Constraints may include: flexibility may be positive or negative but not both at the same time; flexibility and flexibilities of systems are real numbers; $f_{S} \in \mathrm{R}$; SOC of the battery may never be zero but shall be above a set limit of such as $5 \%$ minimum charge, e.g., $S O C_{\min }<S O C$; indoor air temperature is required to be within adaptive comfort ranges; $\mathrm{CO}_{2}$ levels must be below $1000 \mathrm{ppm}$ and other model related constraints.

MILP was used by Siebert et al. [58] to create objective functions relating to specific use cases: maximizing financial return, maximizing bid length, and maximizing power peak.

$$
\operatorname{Max}\left(\sum t \sum r P(t, r) . W(t) . u t\right)
$$


whereby $P(t, r)$ (kW or MW) is the power flexibility provided by the flexible source $r$ for the timestep $t(\mathrm{~s} \min$ or $\mathrm{h}$ ) and is calculated by:

$$
P(t, r)=\operatorname{Res}(t, r) \cdot E(t, r)
$$

Maximizing bid length:

$$
\operatorname{Max}\left(\sum t \operatorname{Bid}(t)\right)
$$

Subject to the constraint:

$$
\sum r \operatorname{Res}(t, r) \cdot E(t, r) \geq \operatorname{Bid}(t) \cdot P_{\min }
$$

Maximizing power peak:

$$
\operatorname{Max}\left(\operatorname{Max} \sum t \operatorname{Res}(t, r) . E(t, r)\right), t \in \tau
$$

A Boolean indicator $\operatorname{Res}(t, r)$ determines if a flexible source $r$ is available to provide flexibility for the duration of timestep $t$. The quantity of power variation is denoted $E(t, r)$ $(\mathrm{kW}$ or MW) as delivered by flexible source $r$ during timestep $t$. An energy price weight, $W(t)$, is applied to time step $t$, relating to electricity price on a scale from 0 to 2.5 . The length of the optimization is denoted by $u t(\mathrm{~s})$. Similar to Equation (19), Bid(t) is a Boolean indicator for bid activation at time $t$. The minimum power that is required to be provided is $P_{\min }(\mathrm{kW})$. The set of possible time intervals from the start of the demand response bid to the end of the event is $\tau$.

A more generalized flexibility optimization formulation, rather than discrete cost functions for different scenarios, would be more advantageous, as would be independent of pricing and market structures in different countries. As an alternative to a weighting factor for price, incorporating actual power or energy prices would be preferred, as the costbenefit to the building or site may then be generated as an output for informed stakeholder decision-making. Binary 1/0 Booleans may minimize or exclude the contribution of sources with partial flexibility as the binary approach may limit the application to on/off sources. For fast demand-side services such as ancillary services, maximizing financial return may be decoupled from bid length and power peak. However, for longer events that may be priced on an energy basis, there may be synergy between maximizing financial return and bid length or power peak. Power peak maximization by increasing consumption may be required in situations with excess renewable generation such that grid balancing necessitates increases in system load, known as positive or forced flexibility [15].

A stochastic approach, also using MILP, was developed by Ottesen and Tomasgard [59]:

$$
\begin{aligned}
\min & \sum_{s \in S} R_{s}\left[\sum_{a \in A} \sum_{t \in T} P_{a, t, s}^{\text {energy }} x_{a, t, s}^{\text {import }}\right. \\
& +\sum_{a \in A} P_{a}^{\text {peak }} x_{a, s}^{\text {peak }} \\
& +\sum_{o \in O} \sum_{y \in Y} \sum_{t \in T} G_{o, y}^{\text {startup }} \alpha_{o, y, t, s}^{\text {start }} \\
& \left.+\sum_{d \in D^{c}} \sum_{y \in Y} \sum_{t \in T} X_{d, y} \Phi_{o, y, t, s}-\sum_{a \in A} \sum_{t \in T} P_{a, t}^{\text {sales }} x_{a, t, s}^{\text {export }}\right]
\end{aligned}
$$

The probability of scenarios is given by $R_{s}$. The grid import power $x^{\text {import }}(\mathrm{kW})$ excludes flexibility $(\mathrm{kW})$. Energy prices are accounted for by $P^{\text {energy }}(€)$. The power consumption in peak periods $x^{\text {peak }}(\mathrm{kW})$, is multiplied by the associated cost penalty $P^{\text {peak }}(€)$, if present. Should the building be supplied from different energy carriers such as electricity, gas, and district heating, the cost of ramping or starting energy conversion is included through $G^{\text {startup }}(€)$ coupled with a binary variable, $\alpha$, to activate and deactivate the energy supply. Curtailment of load and other disutility losses are accounted for by $\operatorname{cost} X_{d}(€)$ multiplied by load reduction $\Phi(\mathrm{kW})$. If export of renewable generation $x^{\text {export }}(\mathrm{kW})$ from 
the building is permitted, and a financial return $P^{\text {sales }}(€)$ is provided by the grid utility, this is also included.

Flexibility is maximized implicitly in Equation (23) through minimizing grid import power. While the concept allows for different energy vectors or energy carriers, such as on-site renewable generation or district heating, to be incorporated, the cost function is focused on electricity optimization. The proposed approach is more generalized than Siebert et al. [58], which is advantageous as it makes it more widely applicable without modifications being required. The optimization assumes certain fixed pricing structures are present in the demand response market, e.g., peak penalties such as critical peak pricing (CPP) and that tariffs are based on $\mathrm{kW}$ or MW consumption. However, it is not clear if the formulation is adaptable enough to incorporate dynamic, real-time, or other pricing signals which may be used in demand-side programs, for example, positive flexibility or capacity markets. Ramping or converter startup costs may be significant for on-site generation, such as combined heat and power (CHP) and frequent cycling may be detrimental to the equipment but are minimal for battery storage systems. On the other hand, efficiency losses due to charging and discharging battery systems are not accounted for. Grid export regimes are specified by grid utilities and vary widely depending on the jurisdictions and size of on-site renewable generation. If export is not permitted, $x^{\text {export }}$ in Equation (23) will be zero, or if it is permitted but not rewarded, $P^{\text {sales }}$ will be null, thereby removing the final term.

An MILP objective function combined with simple models of building systems and an ARX model of building thermal storage used a cost-based approach [31]. Heat pumps may be used for heating or cooling, and in this instance, were used for cooling. The optimization shown in Equation (24) was implemented in Gurobi. The objective was to minimize electrical grid import costs, $\mathrm{PV}$ costs, and cooling system maintenance costs. $\mathrm{P}$ denotes power $(\mathrm{kW})$, Ep is the grid electricity price $(€ / \mathrm{kWh}), \varepsilon$ is the expense of maintaining the PV and cooling systems, denoted by the superscript $C S$, respectively ( $€ / \mathrm{kW}$ installed), $i$ specifies the number of chillers, while the duration of individual time steps, $\Delta \tau$, is one hour (h).

$$
\min \sum_{\tau \in T} P^{\text {grid }} . E p \cdot \Delta \tau+\left(\varepsilon^{P V} \cdot P^{P V}+\varepsilon^{C S} \cdot \sum_{i \in I} Q^{i}\right) \cdot \Delta \tau
$$

The Gurobi optimization software is a commercial solver for linear programming, mixed-integer programming, and quadratic programming [61]. Other similar solvers include Cplex [62] and SCIP [63]. The Gurobi MILP algorithm has been used for a wide range of optimization problems such as process planning in manufacturing [64] and scheduling of container crane loading operations for shipping [65].

While cost may be a factor in many demand response events, it is not universally the case. $\mathrm{CO}_{2}$ minimization, for example, does not have a monetary cost factor. The maintenance cost of the PV system is independent of the time step and PV is not controllable, so it is not clear why it has been included. It is not clear how maintenance costs for the chillers in the cooling system are impacted by participation in demand response events. For split system heat pumps, the most commonly used type in office buildings, compressor cycling on part load is a routine part of their normal operation. Some types of large industrial chillers, e.g., ammonia chillers, do require on/off operation at full load, and cycling may have some slight impact on their maintenance cycles. However, these chillers are installed for large loads. e.g., chill warehousing, or are coupled with purpose-built storage, which dampens cyclic effects.

Elements of each of the above approaches have merit and may be adapted and combined in the development of a more universal objective function for flexibility which is applicable to a wide range of use cases, permits linking to a diverse range of model types and includes pertinent variables. 


\section{Conclusions}

A framework for automating a simultaneous aggregator-based assessment and activation of flexibility in multiple buildings has been developed. Implementation of the framework requires automation of "Step 3: Scenario Modeling" from the flexibility assessment previously developed by the author, which outputs the available flexibility defined for the specific time period of the demand response request for each building or site. Appropriate model types were selected for each flexible system, a data-driven model for the AHU fan, a grey box model for the heat pump system, physics-based for the PV panel, and mathematical for the battery system, incorporating data-driven elements for adaptive efficiency. The models were then adapted for flexibility. The flexibility output from the models is then input to a proposed optimization formulation. Based on a review of optimization applied to the flexibility domain, MILP was found to be the most appropriate approach. Future work includes implementation of the framework in a simulation environment, addressing the technology gaps relating to interoperability of building and site automation systems, and practical installation of the framework at pilot sites to demonstrate use cases and provide experimental results.

\section{Patents}

Riverso, S.; Torchio, M.; O'Connell, S.; Sobonski, P. Managing flexible grid resources. Patent Application No. 62/718,048. Filed with US Patent office 13 August 2018.

Author Contributions: Conceptualization, methodology, writing, S.O.; supervision, M.M.K. All authors have read and agreed to the published version of the manuscript.

Funding: This research was funded by the European Union Horizon 2020 project ELSA (Energy Local Storage Advanced system), grant number 646125. Funding was also provided by the Sustainable Energy Authority of Ireland (SEAI), grant number 400013504.

Institutional Review Board Statement: Not applicable.

Informed Consent Statement: Not applicable.

Acknowledgments: The authors wish to acknowledge the International Energy Agency's (IEA) Energy in Buildings and Communities (EBC) Annex 67'Energy Flexible Buildings' and Annex 82 'Energy Flexible Buildings Towards Resilient Low Carbon Energy Systems' under whose scope this research was performed.

Conflicts of Interest: The authors declare no conflict of interest. The funders had no role in the design of the study; in the collection, analyses, or interpretation of data; in the writing of the manuscript, or in the decision to publish the results.

\section{References}

1. European Commission. State of the Union: Questions \& Answers on the 2030 Climate Target Plan; European Commission Press Corner: Brussels, Belgium, 2020.

2. European Commission. A Clean Planet for all: A European Strategic Long-Term Vision for a Prosperous, Modern, Competitive and Climate Neutral Economy, 28.11.2018 COM (2018) 773 Final; European Commission: Brussels, Belgium, 2018.

3. Jensen, S.Ø.; Marszal, A.J.; Lollini, R.; Pasut, W.; Knotzer, A.; Engelmann, P.; Stafford, A.; Reynders, G. IEA EBC Annex 67 Energy Flexible Buildings. Energy Build. 2017, 155, 25-34. [CrossRef]

4. Lew, D.; Stenclik, D.; Bartlett, D.; Groom, A.; Jorgensen, P.; O’Sullivan, J.; Quint, R.; Rew, B.; Rockwell, B.; Sharma, S. Secrets of Successful Integration: Operating experience with high levels of variable, inverter-based generation. IEEE Power Energy Mag. 2019, 17, 24-34. [CrossRef]

5. Araya Cardoso, A.; Torriti, J.; Lorincz, M. Making demand side response happen: A review of barriers in commercial and public organisations. Energy Res. Soc. Sci. 2020, 64, 101443. [CrossRef]

6. Matevosyan, J.; Vital, V.; O’Sullivan, J.; Quint, R.; Badrzadeh, B.; Prevost, T.; Quitmann, E.; Ramasubramanian, D.; Urdal, H.; Achilles, S.; et al. Grid Forming Inverters: Are They the Key for High Renewable Penetration? IEEE Power Energy Mag. 2019, 17, 89-98. [CrossRef]

7. Rasku, T.; Kiviluoma, A. Comparison of Widespread Flexible Residential Electric Heating and Energy Efficiency in a Future Nordic Power System. Energies 2019, 12, 5. [CrossRef] 
8. Østergaard Jensen, S.; Parker, J.; Marszal-Pomianowska, A. (Eds.) Principles of Energy Flexible Buildings. Deliverable, International Energy Agency Energy in Buildings \& Communities Annex 67 Energy Flexible Buildings. 2019. Available online: https://www.annex67.org/media/1918/principles-of-energy-flexible-buildings.pdf (accessed on 17 August 2020).

9. Foggia, G.; Neto, A.; Michiorri, A.; Bocquet, A. Coordinated Control of Dispersed Battery Energy Storage Systems for Services to Network Operators. In Proceedings of the 23rd International Conference on Electricity Distribution (CIRED) 2015, Lyon, France, 15-18 June 2015.

10. Eirgrid. The DS3 Programme: Delivering a Secure, Sustainable Electricity System. 2018. Available online: http://www. eirgridgroup.com/how-the-grid-works/ds3-programme (accessed on 12 October 2018).

11. Orths, A.; Anderson, C.L.; Brown, T.; Mulhern, J.; Pudjianto, D.; Ernst, B.; O’Malley, M.; McCalley, J.; Strbac, G. Flexibility from Energy Systems Integration. IEEE Power Energy Mag. 2019, 17, 67-78. [CrossRef]

12. Aghaei, J.; Alizadeh, M. Demand response in smart electricity grids equipped with renewable energy sources: A review. Renew. Sustain. Energy Rev. 2013, 18, 64-72. [CrossRef]

13. European Commission. LCE-01-2016-2017: Next Generation Innovative Technologies Enabling Smart Grids, Storage and Energy System Integration with Increasing Share of Renewables: Distribution Network, Horizon 2020 Work Programme 2016-2017: 10. 'Secure, Clean and Efficient Energy'; European Commission Decision C: Brussels, Belgium, 2016.

14. Ma, Z.; Nørregaard Jørgensen, B.; Parker, J. (Eds.) Stakeholders' Perspectives on Energy Flexible Buildings, Deliverable, International Energy Agency Energy in Buildings and Communities Annex 67 Energy Flexible Buildings. 2019. Available online: https://www.annex67.org/media/1911/stakeholders-perspectives.pdf (accessed on 13 August 2020).

15. Knotzer, A.; Roberta, P.; Østergaard Jensen, S. Characterization of Energy Flexibility in Buildings, Deliverable, International Energy Agency Energy in Buildings and Communities Annex 67 Energy Flexible Buildings. 2019. Available online: https: //www.annex67.org/media/1919/characterization-of-energy-flexibility-in-buildings.pdf (accessed on 13 August 2020).

16. O'Connell, S.; Reynders, G.; Seri, F.; Sterling, R.; Keane, M.M. A standardised flexibility assessment methodology for demand response. Int. J. Build. Pathol. Adapt. 2020, 38, 20-37. [CrossRef]

17. Riverso, S.; Torchio, M.; O'Connell, S.; Sobonski, P. Managing Flexible Grid Resources. U.S. Patent 62/718,048, 13 August 2018.

18. European Commission. LC-SC3-B4E-3-2020: Upgrading Smartness of Existing Buildings through Innovations for Legacy Equipment, Horizon 2020 Work Programme 2018-2020, 10. Secure, Clean and Efficient Energy; European Commission Decision C: Brussels, Belgium, 2020.

19. Muzumdar, A.; Modi, C.; Madhu, G.M.; Vyjayanthi, C. A trustworthy and incentivized smart grid energy trading framework using distributed ledger and smart contracts. J. Netw. Comput. Appl. 2021, 183-184, 103074. [CrossRef]

20. Vieira, G.; Zhang, J. Peer-to-peer energy trading in a microgrid leveraged by smart contracts. Renew. Sustain. Energy Rev. 2021, 143, 110900. [CrossRef]

21. Lv, Z.; Chen, D.; Lou, R.; Wang, Q. Intelligent edge computing based on machine learning for smart city. Future Gener. Comput. Syst. 2021, 115, 90-99. [CrossRef]

22. European Commission. Directive (EU) 2019/944 of the European Parliament and of the Council of 5 June 2019 on common rules for the internal market for electricity and amending Directive 2012/27/EU (recast). OJEU 2019, 62, 125-199. Available online: http:/ / data.europa.eu/eli/dir/2019/944/oj (accessed on 10 August 2021).

23. Hu, M.; Xiao, F.; Bagterp Jørgensen, J.; Wang, S. Frequency control of air conditioners in response to real-time dynamic electricity prices in smart grids. Appl. Energy 2019, 242, 92-106. [CrossRef]

24. Burns, D.; Bialecki, T.; Gil, G.; Kathan, D.; Lee, M.P.; Peirovi, S.; Puram, R. 2020 Assessment of Demand Response and Advanced Metering Pursuant to Energy Policy Act of 2005 Section 1252(e)(3). Staff Report; Federal Energy Regulatory Commission (FERC): Washington, DC, USA, 2020.

25. Li, H.; An, Q.; Yu, B.; Zhao, J.; Cheng, L.; Wang, Y. Strategy analysis of demand side management on distributed heating driven by wind power. Energy Procedia 2017, 105, 2207-2213. [CrossRef]

26. Péan, T.; Salom, J.; Ortiz, J. Environmental and Economic Impact of Demand Response Strategies for Energy Flexible Buildings. In Proceedings of the BSO 2018: 4th Building Simulation and Optimization Conference, Cambridge, UK, 11-12 September 2018.

27. Stroe, D.; Zaharof, A.; Iov, F. Power and Energy Management with Battery Storage for a Hybrid Residential PV-Wind System-A Case Study for Denmark. Energy Procedia 2018, 155, 464-477. [CrossRef]

28. Ashrae, A.N.S.I. Standard 55-2013 Thermal Environmental Conditions for Human Occupancy, American Society of Heating Refrigerating and Air-Conditioning Engineers; American Society of Heating, Refrigerating, and Air-Conditioning Engineers, Inc.: Atlanta, GA, USA, 2013.

29. Carlucci, S.; Bai, L.; de Dear, R.; Yang, L. Review of adaptive thermal comfort models in built environmental regulatory documents. Build. Environ. 2018, 137, 73-89. [CrossRef]

30. CIBSE. GVB2/16 CIBSE Guide B2: Ventilation and Ductwork 2016; Chartered Institute of Building Services Engineers: London, $\mathrm{UK}, 2016$.

31. Roels, S.; Bacher, P.; Bauwens, G.; Madsen, H.; Jiménez, M.J. Characterising the actual thermal performance of buildings: Current results of common exercises performed in the framework of the IEA EBC Annex 58-project. Energy Procedia 2015, 78, 3282-3287. [CrossRef]

32. Niu, J.; Tian, Z.; Yakai, L.; Zhao, H. Flexible dispatch of a building energy system using building thermal storage \& battery energy Storage. Appl. Energy 2019, 243, 274-287. [CrossRef] 
33. Zeng, A.; Liu, S.; Yu, Y. Comparative study of data driven methods in building electricity use prediction. Energy Build. 2019, 194, 289-300. [CrossRef]

34. Yildiz, B.; Bilbao, J.I.; Sproul, A.B. A review and analysis of regression and machine learning models on commercial building electricity load forecasting. Renew. Sustain. Energy Rev. 2017, 73, 1104-1122. [CrossRef]

35. Bourdeau, M.; Zhai, X.; Nefzaoui, E.; Guo, X.; Chatellier, P. Modelling and forecasting building energy consumption: A review of data-driven techniques. Sustain. Cities Soc. 2019, 48, 101533. [CrossRef]

36. Ahmad, T.; Chen, H.; Huang, Y. Short-Term Energy Prediction for District-Level Load Management Using Machine Learning Based Approaches. Energy Procedia 2019, 158, 3331-3338. [CrossRef]

37. Jung, W.; Jazizadeh, F. Human-in-the-loop HVAC operations: A quantitative review on occupancy, comfort, \& energy-efficiency dimensions. Appl. Energy 2019, 239, 1471-1508. [CrossRef]

38. Pantazaras, A.; Lee, S.; Santamouris, M.; Yang, J. Predicting the CO2 levels in buildings using deterministic and identified models. Energy Build. 2016, 127, 774-785. [CrossRef]

39. Paudel, S.; Elmitri, M.; Couturier, S.; Nguyen, P.; Kamphuis, R.; Lacarrière, B.; Le Corre, O. A relevant data selection method for energy consumption prediction of low energy building based on SVM. Energy Build. 2017, 138, 240-256. [CrossRef]

40. Coakley, D.; Raftery, P.; Keane, M.M. A review of methods to match building energy simulation models to measured data. Renew. Sustain. Energy Rev. 2014, 37, 123-141. [CrossRef]

41. Wetter, M. Co-simulation of building energy and control systems with the Building Controls Virtual Test Bed. J. Build. Perform. Simul. 2011, 4, 185-203. [CrossRef]

42. Wetter, M.; Fuchs, M.; Grozman, P.; Helsen, L.; Jorissen, F.; Lauster, M.; Muller, D.; Nytsch-Geusen, C.; Picard, D.; Sahlin, P.; et al International Energy Agency Energy in Buildings and Communities Annex 60 Modelica Library-An International Collaboration to Develop a Free Open-Source Model Library for Buildings and Community Energy Systems. In Proceedings of the 14th IBPSA Conference, Hyderabad, India, 7-9 December 2015.

43. De Coninck, R.; Magnusson, F.; Åkesson, J.; Helsen, L. Toolbox for development and validation of grey-box building models for forecasting and control. J. Build. Perform. Simul. 2016, 9, 288-303. [CrossRef]

44. Halimov, A.; Lauster, M.; Müller, D. Validation and integration of a latent heat storage model into building envelopes of a high-order building model for Modelica library AixLib. Energy Build. 2019, 202, 109336. [CrossRef]

45. Bacher, P.; Madsen, H. Identifying suitable models for the heat dynamics of buildings. Energy Build. 2011, 43, 1511-1522. [CrossRef]

46. Reynders, G. Quantifying the Impact of Building Design on the Potential of Structural Storage for Active Demand Response in Residential Buildings. Ph.D. Thesis, KU Leuven, Leuven, Belgium, 2015.

47. Zhou, W.; Yang, H.; Fang, Z. A novel model for photovoltaic array performance prediction. Appl. Energy 2007, 84, 1187-1198. [CrossRef]

48. Atlas Global Weather Database. Athenium Analytics. Available online: https://www.athenium.com/products/atlas/ (accessed on 4 March 2020).

49. Barbato, A.; Capone, A. Optimization Models and Methods for Demand-Side Management of Residential Users: A Survey. Energies 2014, 7, 5787-5824. [CrossRef]

50. Ito, H.; Hanai, K.; Saito, N.; Kojima, T.; Yoshiyama, S.; Fukui, S. Electricity System Reform Requirements: A Novel Implementation Approach to Grid Management and Control. IEEE Power Energy Mag. 2018, 16, 46-56. [CrossRef]

51. El-Baz, W.; Tzscheutschler, P.; Wagner, U. Day-ahead probabilistic PV generation forecast for buildings energy management systems. Sol. Energy 2018, 171, 478-490. [CrossRef]

52. Honsberg, C.; Bowden, S. Solar Radiation on a Tilted Surface. 2019. Available online: https://www.pveducation.org/pvcdrom/ properties-of-sunlight/solar-radiation-on-a-tilted-surface (accessed on 2 November 2019).

53. Solarworld. Sunmodule SW 250 Mono Black/Version 2.0 and 2.5 Frame; Tech. Spec.: Bonn, Germany, 2012.

54. Berrueta, A.; Urtasun, A.; Ursua, A.; Sanchis, P. A comprehensive model for li-ion batteries: From the physical principles to an electrical model. Energy 2018, 144, 286-300. [CrossRef]

55. Sakti, A.; Gallagher, K.G.; Sepulveda, N.; Uckun, C.; Vergara, C.; de Sisternes, F.J.; Dees, D.W.; Botterud, A. Enhanced representations of lithium-ion batteries in power systems models and their effect on the valuation of energy arbitrage applications. J. Power Sources 2017, 342, 279-291. [CrossRef]

56. Gonzalez-Castellanos, A.; Pozo, D.; Bischi, A. Detailed Li-ion battery characterization model for economic operation. Int. J. Electr Power Energy Syst. 2020, 116, 105561. [CrossRef]

57. White, C.; Thompson, B.; Swan, L. Repurposed electric vehicle battery performance in second-life electricity grid frequency regulation service. J. Energy Storage 2018, 28, 101278. [CrossRef]

58. Siebert, N.; Ammari, S.; Cao, X.; Delaplagne, T.; Mamadou, K.; Gaci, O.; Lagorse, J.; Bertone, Y. Scheduling Demand Response and Smart Battery Flexibility in a Market Environment: Results from the Reflexe Demonstrator Project; IEEE PowerTech: Eindhoven, The Netherlands, 2015. [CrossRef]

59. Ottesen, S.; Tomasgard, A. A stochastic model for scheduling energy flexibility in buildings. Energy 2015, 88, 364-376. [CrossRef]

60. Grønborg Junker, R.; Ghasem Azar, A.; Amaral Lopes, R.; Byskov Lindberg, K.; Reynders, G.; Relan, R.; Madsen, H. Characterizing the energy flexibility of buildings and districts. Appl. Energy 2018, 225, 175-182. [CrossRef] 
61. Gurobi Optimizer Reference Manual, Version 9.1, Gurobi Optimization LLC. 2021. Available online: https://www.gurobi.com/ documentation/9.1/refman/index.html (accessed on 28 July 2021).

62. IBM CPLEX Optimizer, IBM. 2021. Available online: https:/ / www.ibm.com/analytics/cplex-optimizer (accessed on 28 July 2021).

63. Solving Constraint Integer Programs Manual, Version 7.0.3, SCIP Doxygen Documentation. 2021. Available online: https: / / www.scipopt.org/doc/html/ (accessed on 28 July 2021).

64. Liu, O.; Li, X.; Gao, L. A Novel MILP Model Based on the Topology of a Network Graph for Process Planning in an Intelligent Manufacturing System. Engineering 2021, 7, 807-817. [CrossRef]

65. Kong, L.; Ji, M.; Gao, Z. Joint optimization of container slot planning and truck scheduling for tandem quay cranes. Eur. J. Oper. Res. 2021, 293, 149-166. [CrossRef] 